\title{
Wenzhou Real Estate Bubble and Rupture Risk Warning
}

\author{
Anping Pan ${ }^{1}$ Dehua Jiang ${ }^{2}$ \\ ${ }^{1}$ College of Civil Engineering, Wenzhou University, Wenzhou 325035, China \\ ${ }^{2}$ Wenzhou Economic Broadcasting Media Group, Wenzhou 325000, China
}

\begin{abstract}
It is known to us all that the excessive bubble in the real estate market can seriously affect the normal development of the national economy, which could cause the hidden dangers of financial crisis. In 2011, A wave of defaults destabilized markets across Wenzhou, which punctured the property price bubble and caused a painful lesson for the regional economy. Therefore, this paper reviews the trend of housing price in Wenzhou from 2006 to 2015, and analyzes the causes of house bubble. In addition, the adjustment process of Wenzhou real estate is of typical significance, which could provide references for current market trend.
\end{abstract}

\section{Keywords}

Housing bubble; Wenzhou; Housing price; Risk.

\section{温州房地产泡沫产生及破裂的风险警示}

\author{
潘安平 ${ }^{1}$ 姜德华 $^{2}$ \\ 1 温州大学建筑工程学院, 浙江温州 325035 , 中国 \\ 2温州广播电视传媒集团经济科教频道, 浙江温州 325000 , 中国
}

摘要: 众所周知, 房地产市场的过度泡沫化会严重影响国民经济的正常发展, 急剧膨胀的房 地产泡沫为金融危机的爆发埋下了众多隐患。2011 年，温州爆发民间借贷危机，刺破了温 州房地产价格泡沫，造成区域经济受严重波及的惨痛教训。本文通过回顾的 2006 年到 2015 年温州房价的变迁走势, 分析了温州房地产泡沫产生及破灭的原因。温州房地产市场的调整 过程具有典型意义，可为当前楼市走向提供借鉴和参考。

关键词: 房地产泡沫; 温州; 房价; 风险

\section{1. 引言}

2016 年底以来，中央提出“房子 是用来住的，不是用来炒的”，说明
中国政府对房地产泡沫本身一直保持 着警觉的。相对应的是，市场对于我 国房地产行业的房价是否存在泡沫， 以及该如何应对潜在的风险也保持高 
度关注。随着房地产价格的上涨, 近 期房价问题热度升温，对房地产的泡 沫会否因为过度膨胀而破灭的担心和 讨论也越来越多。纵观中国房地产历 史, 从局部情况看, 海南和温州等地 区均出现过严重泡沫破灭，造成区域 经济受严重波及的惨痛教训。在温州 是真实存在过房地产抽干实体经济的 现象, 历史教训值得深思。

\section{2. 温州房地产泡沫的形成}

\subsection{6-2011 年间温州房价快速上涨}

在中国经济变迁的版图中, 温州曾 经扮演过一个十分特殊的角色, “温 州模式”曾经一度风靡大江南北。在 房地产市场上，温州也曾同样创造了 很多传奇, 温州炒房团一度横扫包括 上海、北京等在内的多地楼市。与此 同时, 温州本地的房价也伴随着开始 水涨船高。根据笔者的统计, 从 2004 年开始, 温州楼市炒作的现象已表现 的十分明显。很多新开的楼盘, 开盘 之后, 马上遭到爆炒。当年温州市区 住宅销售均价在每平米 6000 元左右。

随着房价的持续上涨, 越来越多的温 州人将房子作为投资品, 也吸引众多 追求暴利的炒作资本进入楼市。一些 楼盘外加价甚至高达 20 多万元（由于 是期房, 买卖双方根本不具备办理房 产证的条件）。2006 年, 市区房价加 速上升, 房价在万元以上的楼盘比比 皆是。尽管国家连续出台宏观调控政 策, 但还是不能改变当年房价的上升 趋势。2008 年, 温州市区商品住房销 售均价每平米 15477 元。接下来温州 楼市的表现只能用“疯狂”两个字形 容。到 2011 年, 市区新建商品房全年 均价为每平方米 34674 元。当年 11 月 份均价最高, 为每平方米 39623 元。 房价最高时的房价收入比约为杭州市
和宁波市的 2 倍。峰值与 2004 年均价 相比, 涨幅近 7 倍。

\subsection{6-2011 年温州房价上涨的原因}

造成温州楼市泡沫化的原因相当 复杂。有宏观经济面的影响, 也有温 州自身的特殊情况。既有制度性的, 又有发展理念和模式偏差层面的。既 有政府、银行的助推，更有房地产商 和投机者 “操纵市场、恶意炒作”方 面的。

（1）当时土地出让供应量少。作 为浙江人口最多、城市化率不足的地 级市, 2005 年至 2009 年温州市区平均 每年供地只有 500 亩左右。比如 2008 年、 2009 年温州市区宅地出让分别为 537.29 亩、437.91 亩, 土地因此显得 稀缺, 市场看涨的预期非常强烈。温 州市区土地出让市场高潮迭起, 大部 分地块都要经过十几轮, 甚至几十轮 竞标才能取得开发权, 溢价率超过 $100 \%$ 、甚至 $200 \%$ 以上的地块也不在 少数。在土地出让市场表现高调的背 后, 是成规模的产业资本进入地产开 发市场。当时温州民营经济十分发 达, 皮鞋、眼镜、打火机等轻工特色 产业闻名遐迩，于是，有一些产业资 金抱团组成所谓的 “财团” 进军房地 产业。比如, 名噪一时的 “中瑞财 团” 就是温州的神力集团、奥康集团 等九家制造业企业组成的，据称 “可 运作资金超过 100 亿元”。

（2）人们投资渠道比较狭窄，楼 市是人们闲余资金比较好的去处。温 州本身民营经济极其发达, 老百姓手 头有一定的余钱，并且投资偏好房地 产。当时，“温州炒房团” 在国内闻 名遐迩, 甚至成了温州的代名词。当 房价上涨时，不仅诱使居民涌入楼 市, 也诱导企业涌入楼市。

(3) 房价经历一个从价值再发现 到形成泡沫的过程, 房价处于上升周 期。2008、09、10 年这三年, 温州市 
区商品住房销售均价实现了上涨三连 跳, 连上三个台阶。分别为 15477 元/ 平方米、 22042 元/平方米、 25032 元/ 平方米。特别是在 2009-2010 年间, 全 国房价经历了一轮上涨, 温州上涨势 头更猛，其中有多个月份是领涨全 国。比如， 2010 年 1 月, 70 个大中城 市住宅价格指数同比上涨 $9.5 \%$, 温州 同比上涨高达 $15.7 \%$ ，位居第一。开发 商也很疯狂, 当年的 11 月 29 日，位 于温州市区的原温师院地块以总价 37.02 亿的价格被温州房企置信房产竞 得, 楼面价高达 3.7 万元/平方米, 成 为当时全国住宅用地单价地王。

（4）民间借贷加杜杆现象严重, 充裕的流动性是房价上涨的主要 “推 手”。2008 年国家应对国际金融危机 而推出 4 万亿经济刺激政策, 导致银 根放松。许多温州企业得到了巨额贷 款后，不是进行原有产业的升级换 代, 而是流进了楼市, 温州实体企业 涉及房地产的投资比重高达 $66 \%$ 。还 有不少温州人炒房加杜杆的路线图如 下: 先是向银行按揭买房, 然后再拿 着的房子到银行做消费抵押贷款, 接 下来再拿贷款的钱买房, 形成了一个 “购房-抵押贷款-再购房” 的循环。事 后观察, 这些行为其实都是在搞击鼓 传花式的博俊炒作, 谁接最后一棒, 那就是高山守望者了。一直到今年 （2017 年）底, 有些楼盘的接盘者还 没有解套。前面提到的原温师院地 块, 楼面价 3.7 万/平方米, 后来房子 建成后, 二手房市场楼盘售价也不到 4 万/平方米。套牢了一大批人。这些过 度杜杆化的房地产市场投机炒作直接 导致了 2011 年的温州金融市场危机。

\section{3. 温州房地产泡沫的破灭}

当楼市像黑洞一样吸引了市场上 大多数资金, 当房地产绑架了地方实 体经济的时候, 泡沫破灭就在所难免
了。温州房地产泡沫破裂后, 房价下 跌过程经历了多个阶段, 持续时间很 长。从 2011 年 9 月算起, 温州房价经 历了连续 40 多个月的下跌, 一直到 2015 年中才触底。温州许多小区的房 价与顶峰相比缩水近 50\%。

\section{1. 温州房价偠持阶段 (2010 年初至 2011 年 8 月)}

2010 年 4 月 17 日, 国务院发布 “新国十条”, 当时房价一直居高不 下的温州在同年 10 月 12 日发布了相 关意见：暂定本市户籍居民家庭及能 够提供 1 年以上本市纳税证明或社会 保险缴纳证明的非本市户籍居民家庭

（包括夫妻双方及未成年子女）只能 在本市新购买 1 套商品住房（含二手 存量房）。也就是说，某个居民家庭 当时无论名下有几套房, 只能再买一 套。从温州一手房市场成交情况看, 成交量走势随政策变化明显。2010 年 初市场销售情处于高温状态, 自 4 月 国十条限购政策出台后，市场成交情 况逐渐进入颓势, 成交均价也自 5 月 起从逐渐上涨的趋势转而下降。尤其 是 4 月份以后, 新开盘的商品住房一 度出现阶段性 “零” 供应的局面, 一 方面是由于前几年温州的土地供应量 不大；另一方面温州实施的 “限购 令” 政策, 也影响了一批存在 “双 拼” 户型项目无法正常开盘; 另外为 遏制房价过快上涨的势头, 临时干预 了部分高价楼盘定价（比如不给核发 商品房预售许可证），从而影响了这 些高价楼盘的上市进度。

临界点发生在 2010 年 10 月, 此 时, 国家四万亿刺激计划进入尾声。 央行的货币政策转向明显, 原来极度 宽松的货币政策转向紧缩。央行先后 连续 5 次加息、 12 次提高存款准备金 率, 结果是银行资金流动性紧张起 来。于是, 银行开始抽资压贷, 要企 业归还贷款。到了 2011 年, 大多数中 
小企业已经无法从银行获得贷款，由 此爆发了温州民间借贷危机。许多借 高利贷者跑路, 有些温州的老板因为 钱还不上就去跳楼。资金危机成为房 价下跌的导火索。

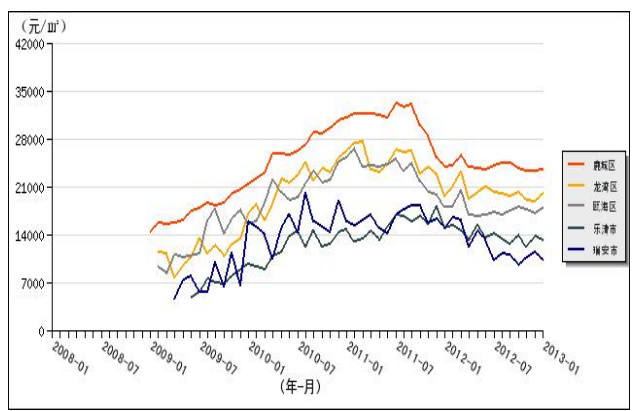

图 1:2009 年 1 月-2013 年 1 月温州住宅历史单 价市场行情

从图 1 中可以明显发现温州房价 造顶的过程。楼市也因为购房者 “买 涨不买跌” 的心理而出现 “越跌越没 人买” 的现象。

\section{2. 温州房价快速下跌阶段（2011 年 9 月至 2012 年 11 月）}

2011 年, 温州房地产市场状况没 有好转, 反而进一步趋冷, 新建商品 房、二手房交易，均出现了同比大幅 下降。比如, 商品房销售面积又比上 年下降 $40.8 \%$ 。

该年 1 月 26 日, 国务院出台新 “国八条”。温州市出台了《关于落 实住房限购政策有关问题的通知》, 当时民间称之为 “温州版” 限购令。 具体规定如下：2011 年 3 月 14 日之 后, 本地户籍家庭及纳税或社保满一 年的非本地户籍家庭只能新购买 1 套 住房, 已拥有 2 套及以上住房的本市 户籍居民家庭等暂停购房。该政策限 制本地户籍家庭购买第 2 套住房, 这 与新 “国八条” 要求、大多数城市实 行的 “限购第 3 套” 政策相比, 更加 严苛。
房地产调控措施特别是限购措施 已经在温州发挥明显作用。在 “史上 最严调控” 的发力下, 温州楼市终于 降声四起, 进入了 “以价换量” 的大 促销阶段, 前期过热的房价和地价得 到回归。长时间的持续大幅下滑使得 房地产企业资金链崩裂，房价的僵持 阶段终于被打破，进入快速下跌的被 动调整阶段。这一阶段的房价下跌幅 度为 $18.5 \%$, 持续时间为 15 个月。

\section{3. 温州房价下跌过渡阶段 (2012 年 12 月至 2013 年 6 月）}

房价下跌有效刺激了住房消费需 求, 再加上全国房地产市场迅速升 温, 温州房地产市场也明显好转, 商 品房销售面积呈现恢复性增长，2012 年比上年增长 $51 \%$, 房价也由下跌转 为稳定, 但走势明显弱于全国。在全 国各大城市房价普遍上涨的情况下, 温州的房价仅为稳定。

虽然 2012 年房价处于下跌过程, 但是从成交量来看, 相较于 2011 年楼 市的全线低迷，2012 年市民显然对买 房卖房的热情增长不少, 而且与往年 不同的是, 特别青崃 “一手房”。温 州市房产登记中心发布的《2012 年温 州市区房产交易分析白皮书》显示, 温州市区新建商品房 2012 年成交量为 67.638 万平方米、 5651 套, 较 2011 年 同期的 11.715 万平方米、956套，分 别增加了 $477.36 \% 、 491.1 \%$ 。成交金 额达 174.882 亿元。

\section{4. 温州房价缓慢下跌阶段 (2013 年 7 月至 2014 年 6 月）}

受资金流动紧张和全国房地产市 场大环境的影响, 温州房价在 2013 年 7 月再次转跌, 到 2014 年 5 月份末下 跌 5.1\%, 下跌速比前一波慢一些。

面对房价的持续走低以及库存的 居高不下的局面, 温州市政府开始出 
手了。在政策面上, 2013 年 8 月, 温 州对原先严苛的限购政策微调, 回归 2011 年新 “国八条” 框架, 规定温州 本地户籍家庭可购买第 2 套住房, 意 味着已购买 1 套住宅的本地户籍家 庭, 可再购买 1 套住宅, 但名下所有 房产只能是 2 套, 之前名下无房产的 可再购买 2 套。

2013 年温州限购政策微调政策影 响, 这一阶段的销售状况继续好转, 2013 年的商品房销售面积创出历史新 高, 比上年增长 $71.2 \%$ 。在土地市场方 面, 温州市区共出让商品房建设用地 65 宗, 出让土地面积 230.75 万平方米

(3401.2 亩)，可建面积 545.3 万平方 米; 其中出让商品住房建设用地 28 宗, 面积 101.94 万平方米（1529.05 亩）, 可建的建筑面积 280.23 万平方 米, 可供应的住宅建筑面积达到了 229.08 万平方米。

\section{5. 温州房价基本企稳见底（2014 年 7 月至 2015 年 6 月）}

在 2014 年 3 月召开的全国两会 上，李克强总理在政府工作报告中指 出: 要针对不同城市的具体情况实施 “因城施策、分类调控”。当年 7 月 29 日, 温州宣布放开限购。具体措施 包括在房屋交易登记时不再核查现有 住房情况, 在外温州人和新温州人在 温购房享受与温州市本地户籍居民同 等待遇。

2015 年, 房地产政策利好的频频 出台落地。在全国层面的政策利好 有：3.30 房贷新政、二套房首付降至 4 成、营业税免征期限 5 年改 2 年、公 积金新政等。而温州市于 4 月 2 日出 台了《关于促进房地产市场持续平稳 健康发展的若干意见》（俗称为 “温 八条” 房产新政）。其中明确提出, 对首次购买新建普通商品住房的购房 者给予补助, 打出政策组合拳, 直指 “促量稳价” 的目标。在多重政策利
好下, 温州 2015 年 4 月份价格指数环 比出现了回升, 新建商品住宅价格指 数环比上升 $0.7 \%$, 二手住宅价格指数 环比上升 $0.4 \%$, 房价基本企稳见底。

\section{4. 温州房地产泡沫的破灭对当前楼市 发展的启示}

温州作为中国楼市 “风向标”, 在历史上曾经出现过的房价下跌、资 本撤离、“弃房”显现等楼市泡沫破 裂迹象, 为全国其他城市狂杀发展的 楼市提出警示。

\section{1. 房价过度投机炒作是引发下跌的总 根源}

当前有些城市与当年的温州一 样, 房地产市场的繁荣主要靠投资需 求拉动, 而实际需求明显不足。大量 的投机性购房, 会放大虚拟需求传递 给人一种虚假的需求讯息。若投机需 求占比过大, 一旦房价失去上涨动 力, 房地产市场的大幅波动就无法避 免, 房价的剧烈调整也在所难免。因 为要想维持住严重过高的房价, 方法 只有一个, 那就是房价继续上涨, 并 且上涨的速度要足够快。房市作为一 个完全依赖于资金推动的市场, 这需 要源源不断的资金流入楼市。一旦资 金投入乏力, 就犹如人之失血, 出现 调整也是理所当然。也就是说, 脱离 实业的楼市 “炒作” 只能是浮萍, 一 旦投资需求被限制，结局是楼市崩 盘、实业受损。

\section{2. 高度警惕房地产业 “绑架” 实体经 济}

经常有人开玩笑说, 中国经济就 是房地产经济。为什么老百姓这么疯 狂地买房? 是因为他们相信房价会一 直涨。对房地产投机的巨额利益, 也 会促使企业大举进军这个产业。有的 企业通过买楼来炒房, 有的企业干脆 
抱团组成财团入股投资房地产。这样 的话，房价事实上成为错综复杂民间 借贷、企业互保链条、银行信贷行为 相互交织的风暴眼。一旦地产市场缩 水后，就会影响企业抵押物的市值， 必然会导致银行缩小这些企业的信贷 规模, “弃房” 现象出现。一旦银行 不良贷款大幅上升，民间借贷信用破 产。经济就会因此受到致命打击。这 样, 一个经济问题可能转化为政治问 题及社会问题。温州的经验表明：任 何一个地方实体经济是基础, 房价是 附属在实体经济之上的一个产物, 脱 离了实体经济支撑的房价必然走向泡 沫。因此, 如何发展好地方的实体经 济, 吸引人口与资金回归, 引导实体 经济向更高层次转型升级, 才是防止 楼市泡沫的根本之道。

\section{3. 严格控制银行信贷资金及各类 “热 钱”进入房地产业}

温州的经验表明, 一旦房地产市 场急剧调整, 极易引爆民间借贷危 机。具体表现在：当房价下跌的时 候，原先 “购房-抵押贷款-再购房” 的 杜杆操作模式不灵了, 很多人开始变 卖房产还贷, 那些企业主的资产也开 始恶化, 还不上的干脆跑路。而企业 主加快套现房产还债的行为, 又加快 房价回落, 从而形成螺旋式传导链 条, 使得风险继续扩散发酵, 导致银 行不良贷款急剧增加。与此同时, 面 对不断上升的风险, 银行只能收紧信 贷甚至停贷, 从而进一步加剧资金紧 张。在市场大环境发生质变的情况 下, 若不及时主动地对房价进行调 整, 那么后果就只能是被动调整, 而 被动调整往往会相当惨烈。

\section{4. 房价回归合理水平其实是有利于房 地产业长远发展}

房价下跌会导致房地产投资性需 求大幅减少, 未来房地产的稳定与增 长, 只能依靠消费性需求。在 “衣食 住行” 中, 居民对住房的消费意愿最 为强烈、潜力最大, 而实现难度也是 最大的。从理论上讲, 凡是从消费角 度出发的需求, 都对消费成本特别敏 感, 特别是首套住房购买者或咬牙买 房者, 温州情况正是如此。房价下跌 对住房消费需求的刺激作用非常大, 住房消费需求的价格弹性相当高。房 价下跌后的 2012 年和 2013 年, 商品 房销售面积均大幅增长, 增速分别为 $50.1 \%$ 和 $71.2 \%$ 。

\section{参考文献}

[1] 余根钱. 温州房价下跌的启示 https://www.qianzhan.com/analyst/de tail/329/140704-6e 7dd407.html.

[2] 温州市房产登记中心. 2012 年温州 市区房产交易分析白皮书, 2013.04.

[3] 周知客. 脱实向虚: 温州地产泡沫启 示 录

http://www.p5w.net/weyt/201611/ t20161118_1640872.htm .

[4] 徐明,胡丹.温州楼市正回暖 曾经房 价连续 40 多个月同比下跌。 http://biz.zjol.com.cn/system/2015/0 6/29/020715476.shtml.

[5] 海通证券. 温州房地产泡沫对当前 楼市的 经验与教 训. http://www.guandian.cn/article/2016 1018/ 179283.html1. 